\title{
Erratum to: Dimethylfumarate induces cell cycle arrest and apoptosis via regulating intracellular redox systems in HeLa cells
}

\author{
Guocan Han $^{1} \cdot$ Qiang Zhou ${ }^{2}$
}

Published online: 14 October 2016

(C) The Society for In Vitro Biology 2016

Erratum to: In Vitro Cell Dev. Biol. Animal

DOI: 10.1007/s11626-016-0069-2

Figure 3 as originally published should be replaced with the correct Figure 3 displayed below.

The online version of the original article can be found at http://dx.doi. org/10.1007/s11626-016-0069-2.

Qiang Zhou

qizhouqiang@yeah.net

Guocan Han

fluid_han@sina.com

1 Department of Radiology, Sir Run Run Shaw Hospital, School of Medicine, Zhejiang University, Hangzhou 310016, People's Republic of China

2 Department of Dermatology, Sir Run Run Shaw Hospital, School of Medicine, Zhejiang University, 3 Qingchun Road East,

Hangzhou 310016, People's Republic of China 
Fig. 3 Dimethylfumarate (DMF) induced HeLa cell apoptosis. The effect of DMF without (a) or with (b) N-acetyl-L-cysteine (NAC) treatmenton cell apoptosis of HeLa cells was evaluated through flow cytometry. (c) The percentage of apoptotic cells in different groups; the protein expressions of caspase- 3 and PARP were detected using western blot assay after DMF treatment without (d) orwith (e) NAC. Column, mean $(\mathrm{n}=3)$; bars, $\mathrm{SD} ; * * * \mathrm{P}<0.001$ vs control group; \#\#\# < 0.01 vs DMF group a
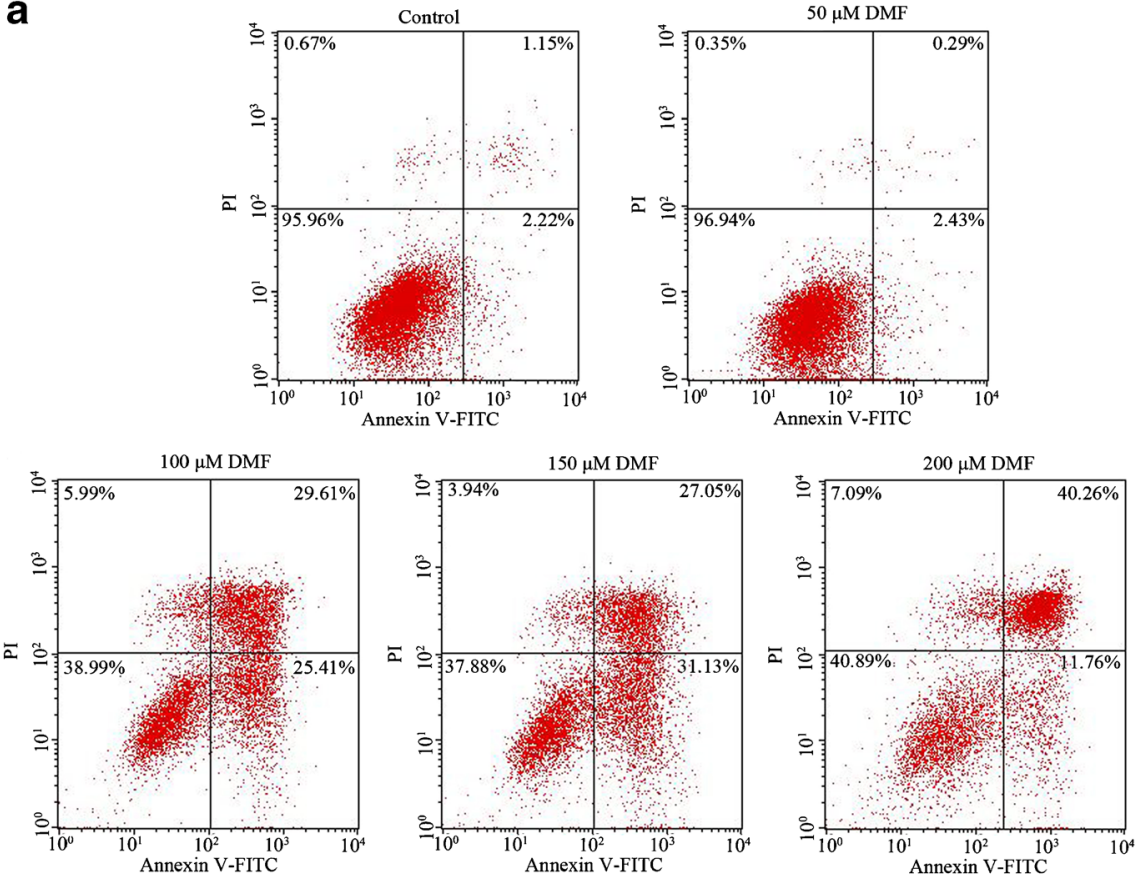

b
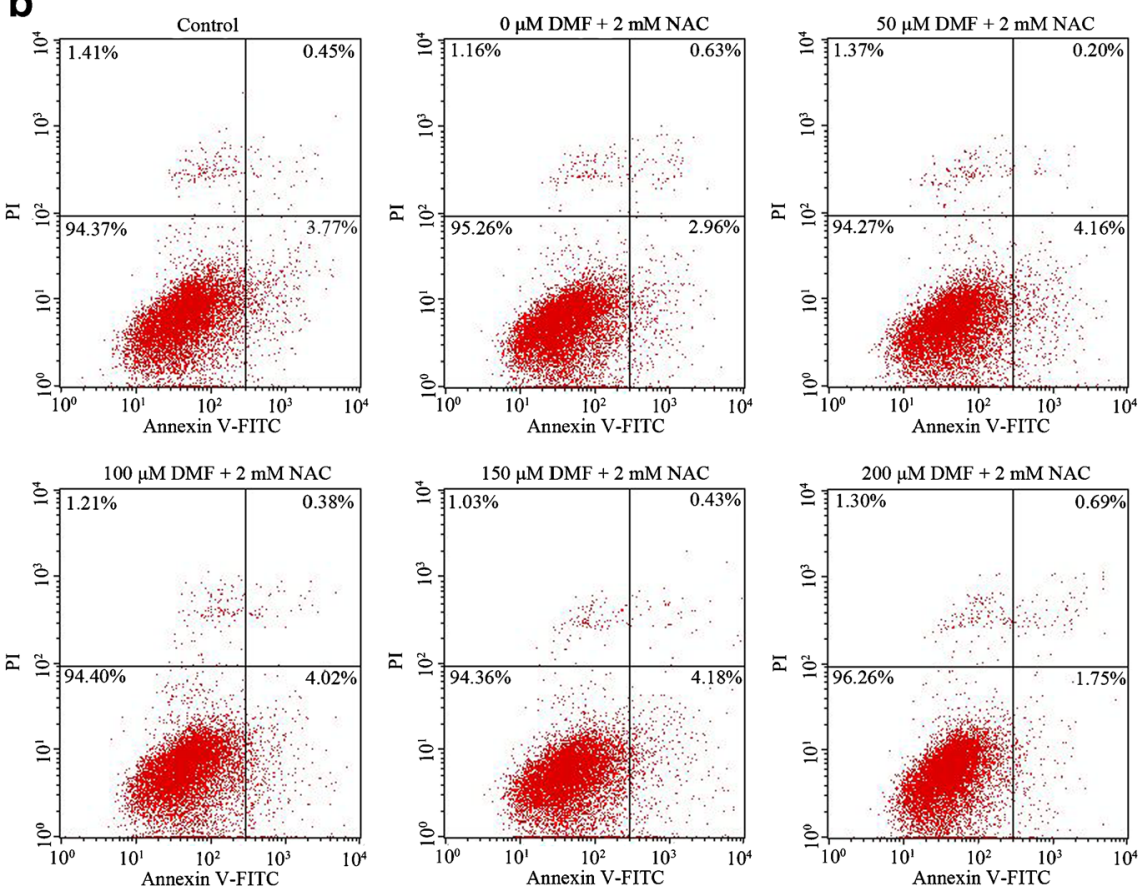

C



d

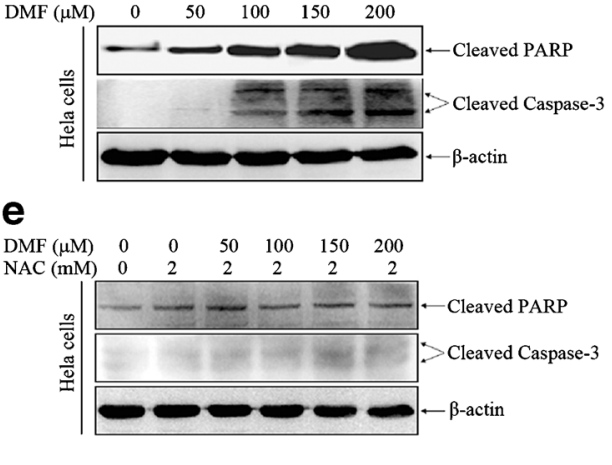

